\title{
Predicted decrease in global climate suitability masks regional complexity of invasive fruit fly species response to climate change
}

\author{
M. P. Hill • C. Bertelsmeier $\cdot$ S. Clusella-Trullas • \\ J. Garnas • M. P. Robertson · J. S. Terblanche
}

Received: 3 December 2015/ Accepted: 14 January 2016

(C) Springer International Publishing Switzerland 2016

\begin{abstract}
Climate change affects the rate of insect invasions as well as the abundance, distribution and impacts of such invasions on a global scale. Among the principal analytical approaches to predicting and understanding future impacts of biological invasions are Species Distribution Models (SDMs), typically in the form of correlative Ecological Niche Models (ENMs). An underlying assumption of ENMs is that species-environment relationships remain preserved during extrapolations in space and time, although this is widely criticised. The semi-mechanistic modelling platform, CLIMEX, employs a top-down approach using species ecophysiological traits and is able to
\end{abstract}

Electronic supplementary material The online version of this article (doi:10.1007/s10530-016-1078-5) contains supplementary material, which is available to authorized users.

\section{P. Hill $(\bowtie) \cdot$ J. S. Terblanche}

Centre for Invasion Biology, Department of Conservation Ecology and Entomology, Faculty of AgriSciences,

Stellenbosch University, Private Bag X1, Matieland 7602,

South Africa

e-mail: matthill@protonmail.com

C. Bertelsmeier

Department of Ecology and Evolution, University of Lausanne, Le Biophore, UNIL-Sorge, 1015 Lausanne, Switzerland

S. Clusella-Trullas

Centre for Invasion Biology, Department of Botany and Zoology, Faculty of Science, Stellenbosch University,

Private Bag X1, Matieland 7602, South Africa avoid some of the issues of extrapolation, making it highly applicable to investigating biological invasions in the context of climate change. The tephritid fruit flies (Diptera: Tephritidae) comprise some of the most successful invasive species and serious economic pests around the world. Here we project 12 tephritid species CLIMEX models into future climate scenarios to examine overall patterns of climate suitability and forecast potential distributional changes for this group. We further compare the aggregate response of the group against species-specific responses. We then consider additional drivers of biological invasions to examine how invasion potential is influenced by climate, fruit production and trade indices. Considering the group of tephritid species examined here, climate change is predicted to decrease global climate

\footnotetext{
J. Garnas

Forestry and Agricultural Biotechnology Institute (FABI), University of Pretoria, Pretoria, South Africa

M. P. Robertson

Centre for Invasion Biology, Department of Zoology and Entomology, University of Pretoria, Pretoria, South Africa
} 
suitability and to shift the cumulative distribution poleward. However, when examining species-level patterns, the predominant directionality of range shifts for 11 of the 12 species is eastward. Most notably, management will need to consider regional changes in fruit fly species invasion potential where high fruit production, trade indices and predicted distributions of these flies overlap.

Keywords Climate change - Trade - Food security · Fruit flies - Tephritidae - Biological invasions . CLIMEX $\cdot$ Species distribution modelling

\section{Introduction}

Global climate change together with elevated volumes of trade, human movement, transport, habitat modification and agricultural production represent key stressors currently impacting ecosystem function, human health and food security (Patz et al. 2005; Thuiller 2007; Brook et al. 2008; Hellmann et al. 2008). Changes including altered climatic constraints and mechanisms of introduction will facilitate the establishment and spread of some organisms outside of their native range (Hellmann et al. 2008). For invasive insects, current research predicts expanded geographic distributions and elevated population densities and/or voltinism under various climate change scenarios (Bale et al. 2002; Harrington et al. 2007; Walther et al. 2009). Further, a non-trivial proportion of agricultural pests are alien and/or invasive insects (Ward and Masters 2007), and thus expected to have potentially serious consequences for sustained agricultural production under climate change (Ziska et al. 2011). General patterns of climate change response for agriculturally important pest insects include poleward range expansion and increased herbivory at higher latitudes (e.g. Bale et al. 2002; Bebber et al. 2013). The search for generality in anticipated climate change impacts is an important component of effective management at a regional or global scale. However, particularly for invasive insects that tend to have disproportionately strong impacts on agricultural production (Ziska et al. 2011), it is becoming increasingly clear that species responses are largely idiosyncratic and must also be understood individually (Dukes et al. 2009; Gutierrez and Ponti 2014).
Among the key determinants of invasion success for insect species are climatic suitability, propagule pressure and the availability of suitable hosts (for parasitic or phytophagous insects; Ward and Masters 2007; Bacon et al. 2014). Climate change is expected to influence the distribution and abundance of invasive insects both directly (e.g., by altering where species and hosts can occur) and indirectly (e.g., via changes in population growth rates, propagule pressure, and spread), amongst other factors (Lantschner et al. 2014). It is important to note that effects of climate change on the distribution and severity of invasive insects may be negative or positive (see Ward and Masters 2007; Bertelsmeier et al. 2015). While each of these key determinants are important, they are often only examined in isolation (Bacon et al. 2014) or may be highly correlated and/or intertwined, such that identifying the principal drivers of new invasions is extremely challenging (Yamanaka et al. 2015). Nevertheless, in order to help control and limit the spread of invasive insect species, understanding the direct and indirect impacts of climate change on invasions is a critical exercise. Further, combining multiple species into a common analytical framework and considering multiple time scales may reveal important general trends or patterns, including the identification of potential "invasion hotspots"-areas that are likely to hold higher-than-expected suitable climate space as a prerequisite for a number of potentially invasive species (Bertelsmeier et al. 2015). To predict how distributions and invasions may change with climate change, Species Distribution Models (SDMs) are widely used (Elith and Leathwick 2009). Typically these are in the form of correlative Ecological Niche Models (ENMs) that aim to describe statistical relationships between environmental variables and known occurrences of species, and to subsequently project these relationships into novel space or conditions (e.g., under different climate change scenarios). Ecological niche models have been used effectively to approximate general patterns of species invasions, including likely introduction points (Fitzpatrick et al. 2007), assessments of invasion risk as a function of climate change (Bertelsmeier et al. 2013a, 2015), and generating hypotheses concerning invasion range extents that can then be tested experimentally (Hill et al. 2013).

Using correlative ENMs for extrapolation of species-environment relationships assumes that they 
remain stable, both temporally and in novel environments. This assumption is often violated (JiménezValverde et al. 2011; Webber et al. 2011), particularly when using ENMs to examine synergies between climate change and invasions (see Bertelsmeier et al. 2013a, b). Thus, SDMs that rely on at least a partial mechanistic understanding of the species-environment relationship are perhaps more appropriate tools in predicting distributions under climate change and biological invasion scenarios. One such SDM is CLIMEX (Hearne Scientific Software Pty Ltd, Australia) (Sutherst and Maywald 1985; Sutherst et al. 2007) which employs a semi-mechanistic approach to examine the relationship between climate, species distributions and patterns of growth (Macfadyen and Kriticos 2012). CLIMEX models are typically fitted using a combination of empirically measured life history parameters (e.g. ecophysiological traits and developmental rates), abundance data and point distribution records. The CLIMEX software calculates a weekly Growth Index (GI) based on species physiological response curves for temperature and soil moisture availability. This GI is then combined with stress indices (e.g. hot/cold and wet/dry) to calculate an Ecoclimatic Index (EI) (Sutherst et al. 2007; Macfadyen and Kriticos 2012). The EI can then be determined across spatially explicit climate data to estimate the suitability of each grid cell (ranging from completely unsuitable to optimal) (see methods; Sutherst et al. 2007). CLIMEX is thus able to avoid some of the issues of transferability associated with ENMs, as the model is rebuilt de novo for climate change scenarios rather than being extrapolated from current distributional estimates (Webber et al. 2011). Thus, CLIMEX is well suited for investigating the interactions between biological invasions and potential responses to climatic change (e.g. Mika and Newman 2010; Lozier and Mills 2011; Hill et al. 2014).

The tephritid flies (Diptera: Tephritidae), or "true fruit flies", are some of the most successful invaders and are serious economic pests around the world (Aluja and Mangan 2008; Papadopoulos et al. 2013; Karsten et al. 2015). The pest flies in this family typically cause major damage to fruits, especially via larval feeding, though damage from oviposition also occurs (Aluja and Mangan 2008). Strict phytosanitary and trade regulations enacted to manage invasive spread can result in indirect economic losses (Duyck et al. 2004; De Meyer et al. 2008). In addition there is increasingly well-documented history of invasions of various tephritid species globally, which have continued to spread rapidly despite major efforts to control their movement (see Duyck et al. 2004; 2007; Hill and Terblanche 2014; Papadopoulos et al. 2013). Tephritid invasions are thought to be primarily associated with the global transport of fruit. Recent analyses of invasion pathways for Ceratitis capitata support this hypothesis, for at least the last two centuries (Karsten et al. 2015). More recently, passenger baggage for air travel has revealed itself as a major pathway (Liebhold et al. 2006; Ma et al. 2012), and that these introductions are not isolated events but rather occur with some regularity. This is seen in examples which include a number of pest tephritids that are continually reappearing in California (Papadopoulos et al. 2013), a large increase in the number of $B$. latifrons interceptions in China in recent years (Ma et al. 2012) and Bactrocera dorsalis (previously B. invadens) intercepted repeatedly in traps in northern South Africa after spreading from recent introduction in Kenya (Manrakhan et al. 2011).

Tephritids are an excellent system for examining how climate change might influence biological invasions of insects. Many of the pest species within the genera Anastrepha, Bactrocera and Ceratitis spp. occupy largely overlapping ecological niches including broadly similar life-histories. Whilst many of these tephritid species have polyphagous diets, others such as those within the genus Rhagoletis are specialists, although this may be on a widely planted fruit crop such as apples ( $R$. pomonella) (Aluja and Mangan 2008). Thus, the general ubiquity of host plants for these species has facilitated the global invasion of many of these species. Many of the pest tephritids also have tropical origins (although temperate for Rhagoletis spp.), and thus any poleward range expansion associated with changing climate opens an abundance of new habitat for these species, in many cases into regions with high fruit production (Stephens et al. 2007; Ni et al. 2012; Fu et al. 2014). Specifically, climate warming in temperate regions improve conditions for the flies to establish, through fewer frost days, a longer growing season and greater frequency of warm nights (Papadopoulos et al. 2013). Tephritids often have high dispersal ability and rapid growth and reproductive rates, as is characteristic of many invasive species and agricultural pests (Tscharntke et al. 
2005). Competition between invasive tephritids is a possibility when there is a shared pathway resulting in multiple species introduction, and resident host plants are limited (e.g. Duyck et al. 2004, 2007). In such cases it may that the successful invaders are the better competitors than resident species, and better colonists than the other invaders (Duyck et al. 2007). Overall however, local biotic resistance from endemic species and natural enemies appears to be low for the highly pestiferous species. Finally, due to their important pest status and the amount of research that is directed at this group, there have been numerous attempts to model current and potential distributions for members of this fly family (Yonow and Sutherst 1998; Vera et al. 2002), several using CLIMEX. Although there are a few individual assessments (Stephens et al. 2007; Ma et al. 2012; Ni et al. 2012; Fu et al. 2014), a comprehensive assessment of their responses to global climate change has not yet been explored.

Here we examine how climate change may alter patterns of geographic distributions through global climatic suitability for a number of tephritid species, both individually and across this group. We first collate SDMs that have been built in CLIMEX, and project them into both baseline and future climate scenarios. We next identify regions of overlap in climatic suitability of these key invasive species in an attempt to highlight areas where additive or synergistic effects of invasion may occur, allowing for the identification of putative invasion hotspots. We further extend these climatic models and combine outputs with information on trade (correlated with invasion risk; Bacon et al. 2014; Lantschner et al. 2014) and fruit production (a reasonable proxy for agricultural host availability; Bacon et al. 2014) to enhance the predictability of invasion potential and impacts in light of three core drivers of invasion success: climate, host availability and dispersal barriers. We contrast our results to what is generally expected for climate change impacts on invasive insect species; namely poleward expansion, increased distributional range and elevated invasion potential.

\section{Methods}

Model parameters

There are a number of tephritid CLIMEX models present in the literature and included with the
CLIMEX software. CLIMEX (Version 4.0 beta) currently ships with model parameters for the following tephritid fruit fly species: Bactrocera tryoni (Yonow and Sutherst 1998), Bactorocera dorsalis (Stephens et al. 2007) and Ceratitis capitata (Vera et al. 2002). These parameters are populated from the literature which has established key physiological and population growth parameters such as thermal tolerance, desiccation tolerance, growth rates and phenology (see Table 1, and references therein). This combination of data from different sources allows for testing and validation of the model using both empirical data and field observations (e.g. Macfadyen and Kriticos 2012). The focus of this study was to look at general patterns of invasion potential with climate change, rather than provide fine scale risk assessments of establishment for any particular species or region. We collated 9 additional models to those included with CLIMEX (Table 1) to give a total of 12 parameterised tephritid models. The different genera represented were Anastrepha (A. ludens, A. obliqua), Bactrocera (B. dorsalis, B. correcta, B. latifrons, B. tryoni, B. zonata), Ceratitis (C. capitata, C. rosa), Rhagoletis ( $R$. pomonella, $R$. indifferens) and Zeugodacus cucurbitae (Previously B. cucurbitae; Virgilio et al. 2015). We assumed that models built on subsets of their range (e.g. Z. cucurbitae in China; Lingbin et al. 2008) would generally perform well when projected to a global surface, though perhaps conservative in their predictions. We used CLIMEX 4.0 (beta version) to rebuild these models and produce spatial outputs of Ecoclimatic Index (EI). At each grid cell the EI scale ranges $0-100$, with 0 representing an unfavourable environment, values over 20 considered to be ideal conditions, between 10 and 20 suitable, and between 0.01 and 10 marginal (Sutherst and Maywald 2005; Ni et al. 2012), though interpretations of EI are speciesspecific to some extent.

\section{Environmental data}

All climatic data were obtained from the CliMond dataset (Version 1.2; Kriticos et al. 2012). The baseline climate reflects average conditions between 1961 and 1990 with 1975 as a midpoint of these data. CLIMEX models were initially predicted to the baseline data for each species. For climate change projections, we used the CSIRO Mk. 3.0 and Miroc-H 
Table 1 CLIMEX parameters for 12 species of tephritid fruit flies

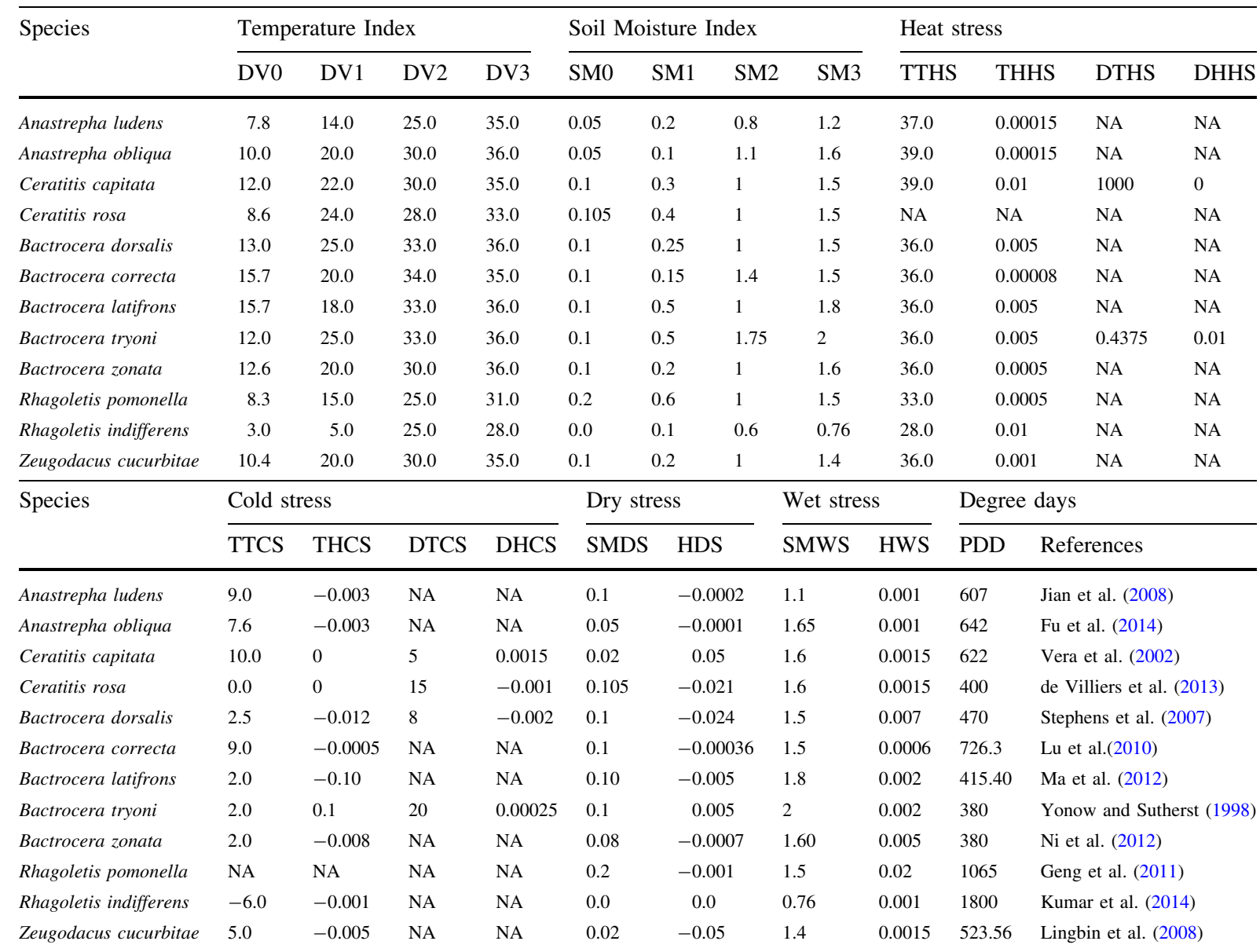

Temperature threshold $\left({ }^{\circ} \mathrm{C}\right)(\mathrm{DV} 0=$ lower temperature threshold, DV1 = lower optimum temperature, DV2 = upper optimum temperature, DV3 = upper temperature threshold); Soil moisture threshold (SM0 = lower soil moisture threshold, SM1 = lower optimum soil moisture, SM2 = upper optimum soil moisture, SM3 = upper soil moisture threshold); Heat stress (TTHS = Heat stress temperature threshold $\left({ }^{\circ} \mathrm{C}\right)$, THHS $=$ Heat stress temperature rate, DTHS = Heat stress degree-day threshold, DHHS $=$ Heat stress degree-day rate); Cold stress $\left(\right.$ TTCS $=$ Cold stress temp threshold $\left({ }^{\circ} \mathrm{C}\right)$, THCS $=$ Cold stress Temperature rate, DTCS $=$ Cold Stress degree-day threshold, DHCS = Cold stress degree-day rate); Dry Stress (SMDS = Dry stress threshold, HDS = Dry stress rate); Wet stress (SMWS = Wet stress threshold, HWS = Wet stress rate); PDD is the number of degree-days per generation. Diapause index (Rhagoletis pomonella only; DPD0 = Weekly day length that induces diapause [12], DPT0 = Weekly minimum temperature that induces diapause [20], DPT1 = weekly minimum temperature that terminates diapause [5], DPD = Minimum number of days for diapause development to be completed[83]). Refer to the CLIMEX manual for further explanation of the units and derivations of these parameters

models (available from CliMond) for the time periods 2030, 2050 and 2070 under the A2 SRES for future climate change. The A2 SRES represents one of the higher rates, though not the highest, of warming in the Fourth Assessment Report (AR4; IPCC 2007). We then predicted the CLIMEX models on the same climate change scenarios and time frames globally, and then averaged the EI across the CSIRO and Miroc$\mathrm{H}$ models for each time frame (as in Hill et al. 2014). As we are most interested in broad scale patterns across countries, and as most of the models were initially parameterised at this resolution, we employed 
a resolution of $30 \mathrm{~min}$, approximately $50 \times 50 \mathrm{~km}$ at the equator.

\section{Distribution changes}

We built spatial raster files from the CLIMEX output using the raster package (Hijmans 2015) in R (R Core Team (2015), version 3.2.1). Using the EI values, we calculated the net change in climate suitability (area expressed in grid cells) for each species and time point. To examine the tephritids as a whole, grid cells were selected at a binary suitability threshold (EI $>10)$ for each species and each time point (baseline, 2030, 2050, 2070), and then combined into single maps to determine current and future climatically suitable areas and potential "invasion hotspots". Beta diversity values including species turnover and nestedness were then calculated by comparing the combined predictions for all 12 species between the baseline and 2070 climates, using $\mathrm{R}$ and following the same approach as used in Bishop et al. (2015). Species turnover is a measure of non-overlap among the species considered and in this case is based on suitable climate space for each grid cell at baseline versus 2070. Nestedness maps display absolute species losses relative to the baseline group, ignoring species gains (Baselga 2010).

To investigate species individually, the baseline time period was compared to the model projections for 2070 to compare potential range increases and decreases (see Delean et al. 2013). For each species the grid cells that changed with projected climate change were classed as either "lost", "gained" or remained as "stable range". Global net change was then calculated by (Gains-Losses)/stable range. We also measured the amount of overlap between the baseline conditions and the three future time periods across the whole global surface for each individual species using Schoener's $D$ (dismo package in R; Hijmans et al. 2015). In addition to losses and gains, we measured the amount of change and calculated the movement of the range margins of each species (range shifts). Range shifts were calculated using the sp (Pebesma and Bivand 2005) and raster packages in R, at $15 \%$ of the range margin in each cardinal direction (North, South, West, East) and the vector connecting the range margin in 1975 and the range margin in 2070. In addition, the vector of the movement of each distribution's centroid was calculated by connecting the centers of gravity in 1975 and 2070.

\section{Additional drivers}

We employed a simple measure of risk by relating climate suitability to fruit production and total agricultural trade data. Data for total fruit production, including melons, was obtained for all countries for the time period 2009 to 2013 from the FAO (FAO 2015). While total fruit production does not take into account the relative proportions and suitabilities of hosts for each tephritid species, nor for the group as a whole, it is a reasonable and considerably more tractable parameter that we hypothesize will broadly correlate with the overall availability of hosts at a landscape scale. For each country, the quantity of fruit production (kilotons) was calculated across these years and mapped by country, but most islands were excluded from the analysis. As a proxy for propagule pressure, we investigated trade data. Data for trade indices, including an import and an export quantity index for agricultural production, was obtained for the years 2007 to 2011 (FAO). Average values across these years were determined and then this was mapped by country. As there are no data on projected trade or fruit production rates, this analysis was carried out for the baseline time period only. In this way we are assuming that high levels of trade will correlate with increased pathways for these fruit flies, but not necessarily trade of specific fruit products. This method does not specifically account for movement via other pathways such as air passenger baggage (Liebhold et al. 2006).

We then examined how indices of import, export and fruit production related to the countries for which there was suitable climate space (determined through the CLIMEX models) and whether the species had been recorded as present or absent in that country (CABI Invasive species compendium; http://www. cabi.org/isc/ accessed July 2015). For example, suitable climate space, high fruit production for a given location and a high import index with a species not recorded may correspond to higher risk of invasion. Conversely, high export index, high level of fruit production and the presence of a tephritid species may indicate a higher risk of contributing to invasions. For each of the 11 species ( $R$. indifferens was excluded from this analysis due to lack of data), we selected all 
countries that hold a $50 \mathrm{~km}$ grid cell with an EI $>10$ and either a presence or absence for that species. We determined two separate indices, first using the presences, we multiplied the export index with the fruit production index, and secondly, using the absences we multiplied the import index with the fruit production index (fruit production was $\log _{10}$ transformed prior in both cases). Here we assume that fruit production will correlate with available hosts and that trade indices will correlate with propagule pressure, ignoring differences in quarantine and detection programmes across these different countries. These indices provide a simple risk analysis of invasion or export potential for each country, and when summed up across all species allows invasion or escape potential for each species/country to be ranked. Our method also makes the assumption that all fruit production and trade will include suitable hosts for a given species. Due to recent taxonomic changes (Schutze et al. 2015), we combined data for $B$. invadens with $B$. dorsalis.

\section{Results}

Distributions and climate change

The CLIMEX model parameters for the 12 species of tephritid fruit fly are shown in Table 1. The global projections of all the species demonstrate that they have very wide potential niches, with suitable climate space available for most species throughout tropical, subtropical and temperate regions (see Supplementary Material 1 for individual species maps). The current climate suitability for the group of all species considered is very broad, distributed throughout equatorial and subtropical through to temperate regions, and particularly in the Southern Hemisphere (Fig. 1a). Sub-Saharan Africa and South America especially are highly suitable (the highest number of species in any grid cell is 12), as are South east Asia and northeastern Australia. North America, Europe and Russia are marginal from a climate suitability standpoint for this group of species (Fig. 1a). Under the climate change scenarios investigated here the climate suitability pattern remains similar to current conditions, though there are noticeable contractions in central (equatorial) South America and Africa, as well as a general decrease in suitable climate space for the tephritid group in Southeast Asia, Australia and India. Marginal suitability observed in North America and Russia under current climate expands under future climate change scenarios (Fig. 1b-d), largely driven by $R$. indifferens and $R$. pomonella (Supplementary Material 1.12-13).

Maps of beta diversity are useful for understanding how species composition is likely to change between baseline and future climate projections. Overall, tephritid community composition is predicted to change most dramatically in northern and eastern Europe, parts of North America, interior India, South America and Australia, and in tropical and temperate sub-Saharan Africa (darkest areas in Fig. 2a-c) according to the 2070 climate projections. Regions of large potential differences in composition occur on all continents and include tropical regions of South America and Africa, parts of southern Africa, parts of Europe and North America ( $\beta$ sor; Fig. 2a). Compositional changes due to species turnover ( $\beta$ sim; Fig. $2 b$ ) appear to be high in the regions where large overall differences in composition are predicted (Fig. 2a) suggesting that turnover appears to be largely responsible for the differences in overall composition. Compositional changes due to nestedness ( $\beta$ sne; Fig. 2c), where high values indicate areas of greatest potential loss of species in future, were at their peak in tropical Africa, southern Africa, tropical regions South America, Southeast Asia and India. A large region of moderate nestedness occurs across most of central Africa, indicating a potential loss of species in this region in future. There are also large areas of moderate nestedness across most of Europe.

Range shifts, niche overlap and climate change

When examined individually, all species display a decrease in climate suitability under the A2 SRES for all time periods, except for $R$. pomenella that shows increases under all time periods, and B. correcta that has slight increases in climate suitability for 2030 and 2050, but a loss at 2070 (Fig. 3a). Niche overlap between the baseline conditions and the different time frames for climate change under the A2 scenario, as measured using Schoener's $D$ (Fig. 3b), reflects that not only is climate suitability generally decreasing, but that the potential niches for each species are becoming increasingly dissimilar. For $R$. pomonella, the overlap also decreases indicating that the gains in climate suitability under climate change are also driving 

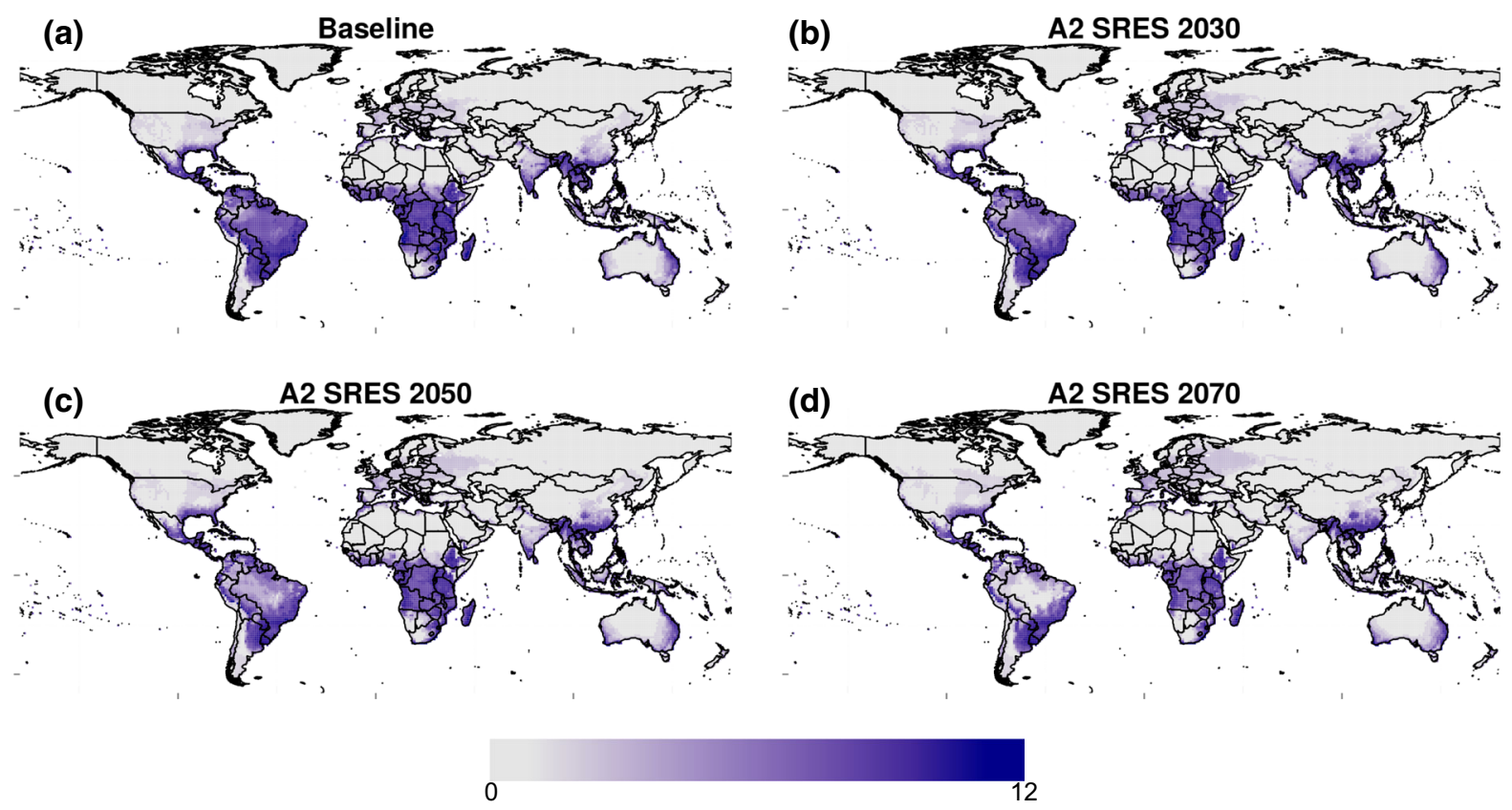

Fig. 1 Suitable climate space for 12 species of tephritid fruit flies for a baseline climatic conditions (1961-1990 centered on 1975) and future climate change (A2 SRES for b 2030, c 2050 and d 2070 time periods). Each species is equally weighted at the threshold value of the Ecoclimatic Index $(\mathrm{EI})>10$. The

elevated dissimilarity from baseline conditions (Fig. 3b). The change in climate suitability maps for each species, indicating which grid cells are "lost", "gained" or maintain a "stable range" between the baseline conditions and 2070 are presented in Supplementary Material 2 and data underlying the shift metrics are available in Supplementary Material 3. The range shifts by species ('shift vectors') reveal a more complex pattern of distributional changes across latitudes (Fig. 4) relative to simple poleward expansion. For most species (11 of 13), the greatest change is eastward, with lesser shifts towards the southern or northern range margins (Fig. 4). In combination with these range margin changes there were also centroid shifts (see Supplementary Material 2 and 3).

\section{Additional drivers}

From our simple classification scheme, we ranked potential invasion risk for countries by determining which hold suitable climate space, the presence or absence of each species, and the fruit production and trade (import and export) indices. The top 15 countries shading indicates number of species that have suitable climate space for a given grid cell, with a value of 0 indicating the grid cell is not suitable for any species, through to 13 indicating that all species have the potential to occupy that grid cell

that are most at risk of exporting a fruit fly species include India, Thailand, the United States of America and countries in eastern sub-Saharan Africa (Fig. 5, red shading). Countries throughout South America, Spain, Turkey and New Zealand have the highest risk of import of a new invasive fruit fly species (blue shading). For some countries, such as Indonesia and Vietnam, both the import and export risk of invasive tephritids is high (purple shading). Typically, the countries at risk of importing fruit flies under baseline conditions also maintain suitable climate space under future climate change. Likewise, the potential sources are countries that have many endemic tephritid species and are also mostly developing countries that are experiencing increases in trade (and see Supplementary Material 4).

\section{Discussion}

Our approach of simultaneously considering species separately and as a group demonstrated that overall patterns of climate change response may mask the complexity of individual range shifts and species 
Fig. 2 Global species turnover and nestedness of tephritid species under climate change. Ecoclimatic Index values of 10 or more were taken to represent suitable climate space per species for each map. a Total compositional variation between a group of tephritid fruit flies for 1975 and 2070, calculated using $\beta_{\text {sor. Darker areas show }}$ highest variation.

b Compositional changes between a group of tephritid fruit flies for 1975 and 2070 that are due to turnover, calculated using $\beta_{\text {sim }}$. Darker areas show greatest turnover in species composition.

c Compositional changes between a group of tephritid fruit flies for 1975 and 2070 due to nestedness,

calculated using $\beta_{\text {sne. }}$. Darker areas show greatest loss in species from 1975 to 2070
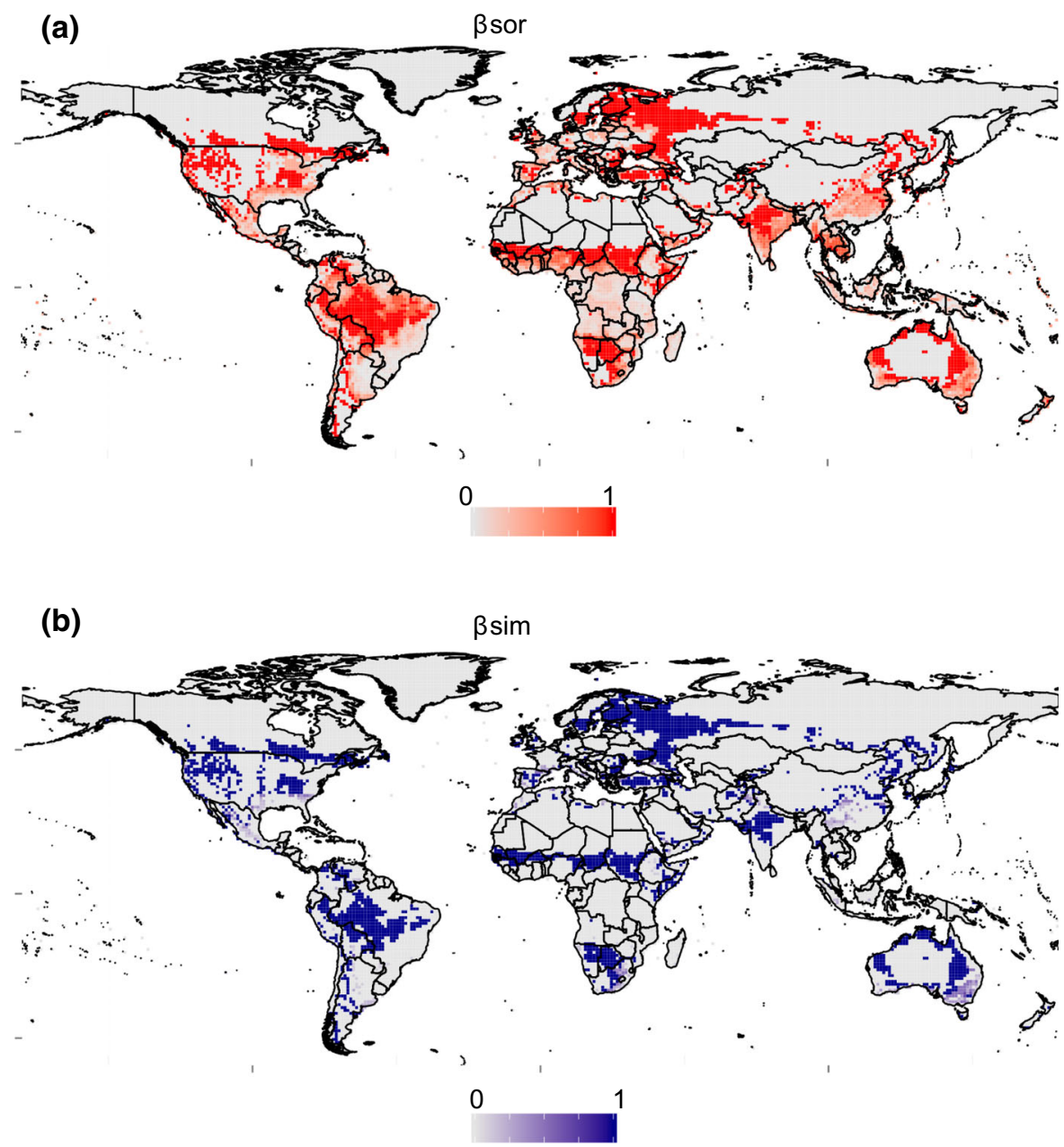

(c) $\beta$ sne

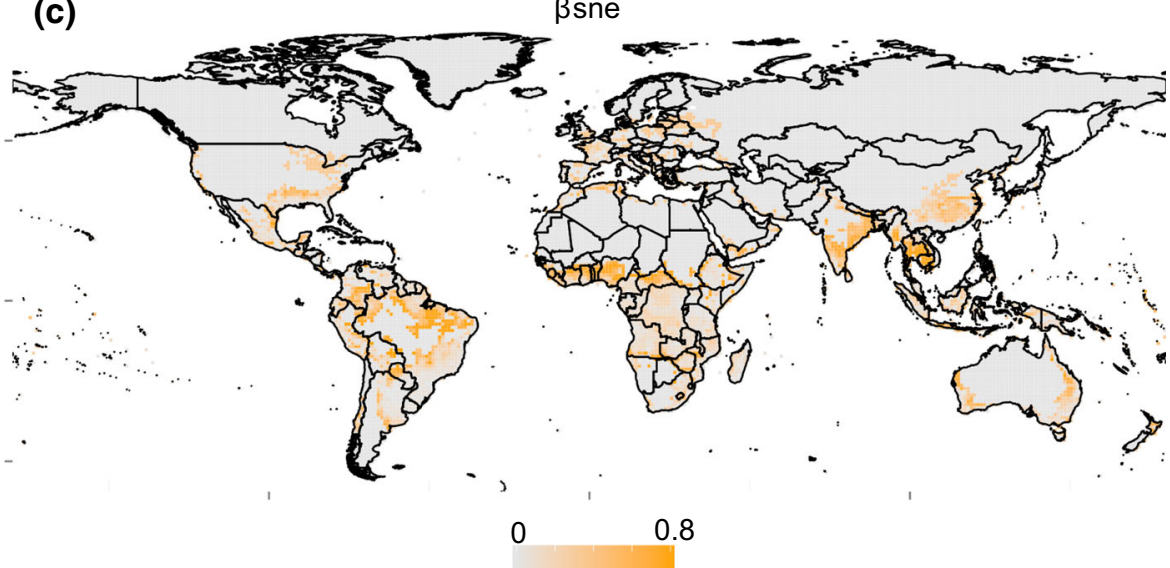

turnover. Climate change is predicted to alter global climate suitability for this group of tephritid species, and the combined shift in distributions is expected to be poleward, mainly through contraction from equatorial regions. Within regions showing preserved or enhanced climate suitability, species display varying 

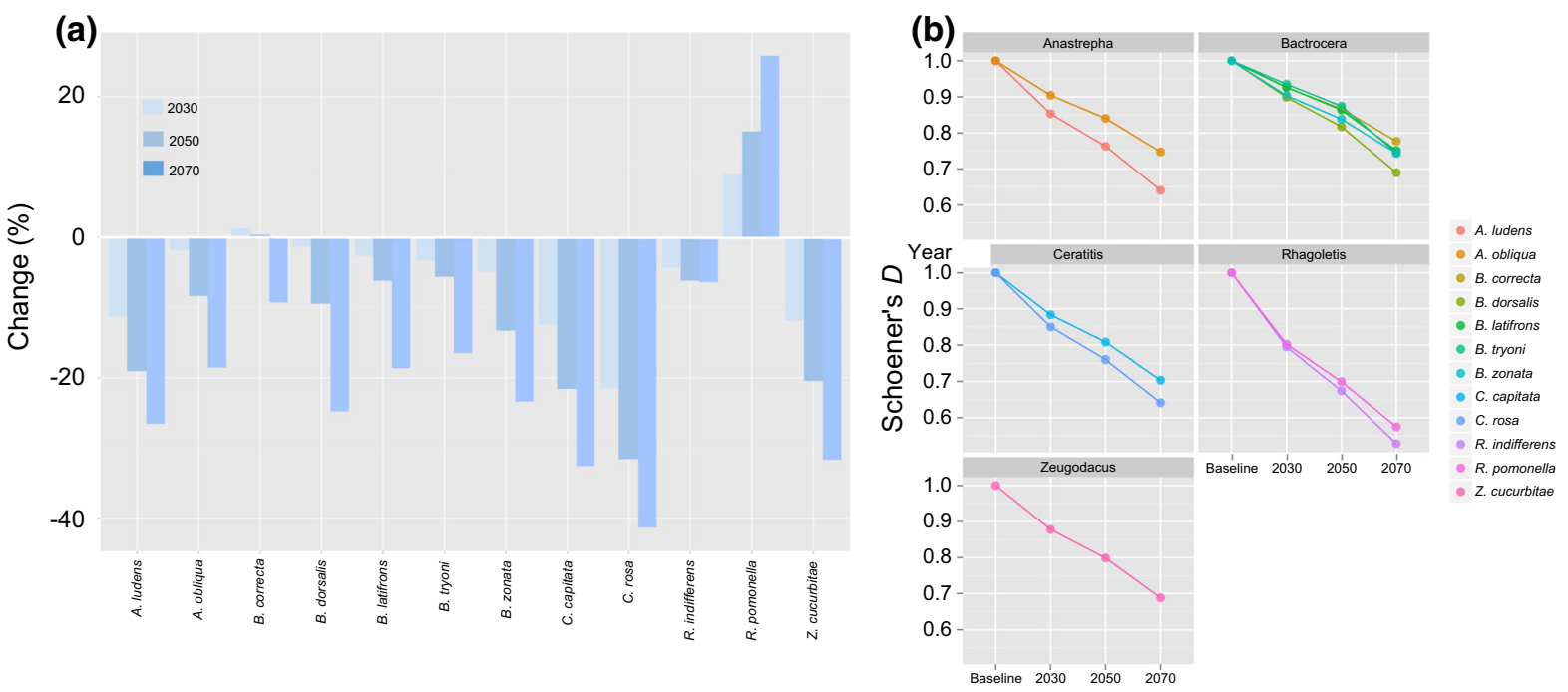

Fig. 3 Range size and niche changes under climate change for 12 species of tephritid fruit flies. a Potential geographic range size changes measured as losses or gains of grid cells under climate change (A2 SRES for 2030, 2050 and 2070 time

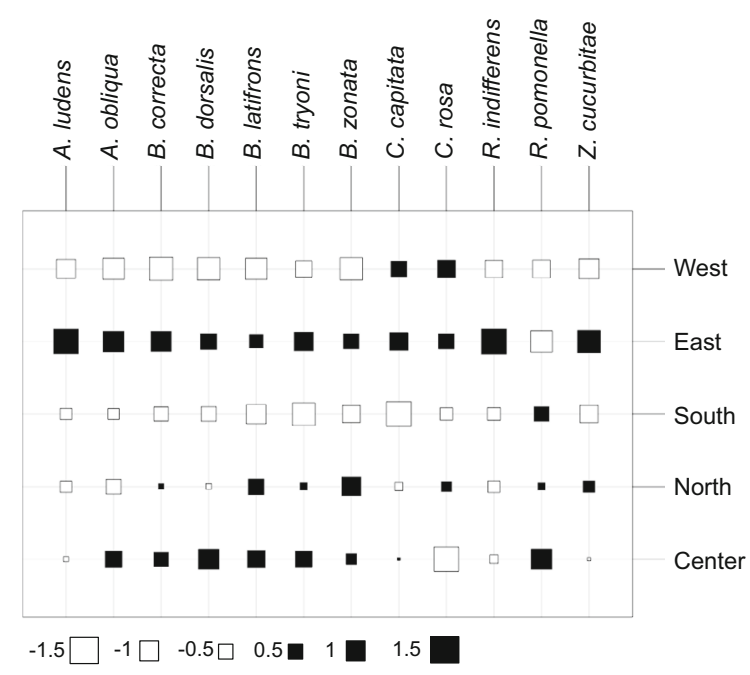

Fig. 4 Comparison of the magnitude and direction of range shifts calculated for 12 tephritid species. Range shift distance was calculated as shift vectors of the range margins and the movement of the centroid vector between the predicted distributions for baseline and 2070 climates. Values are unitless as they are centered on the mean and divided by the standard deviation. White range contraction (negative values), Black range expansion (positive values. represents by small and large squares respectively). To see the direction of individual species shifts, refer to species maps in Supplementary Material 2

levels of expansion and contraction, driving species turnover at the grid cell $\left(50 \mathrm{~km}^{2}\right)$ level. Such patterns are difficult to generalise across species. Indeed, when periods). b Temporal fidelity in niche overlap (calculated as Schoener's $D$ ) between baseline conditions and three future time points $(0=$ complete dissimilarity across time points, $1=$ no change)

considered individually, there is global reduction in climate suitability for each species, except for $R$. pomonella. However, the principal direction of range shifts is eastward, rather than poleward shifts anticipated by most studies predicting distributional range changes under warming (Stephens et al. 2007; Ni et al. 2012; Fu et al. 2014). An eastward range shift may be associated with complex interactions between temperature and precipitation (see Lenoir and Svenning 2015). Such complexity and idiosyncratic species responses suggest that predicting and managing future invasions of these fruit flies and other pest species will be a dynamic and enduring challenge.

The response of tephritid distributions to climate change has been predicted to be primarily poleward, linked to a release from cold stress conditions in higher latitudes under climate change. Climate change is also expected to benefit certain species, such as A. obliqua, which was predicted to expand its range on all continents (Fu et al. 2014). We did not observe such a benefit for the majority of species investigated here, including A. obliqua. This discrepancy may be due to the differences in climate data used (Fu et al. applied a uniform increase in temperature and precipitation instead of an SRES), the time frame for future projections (i.e., 2020 in $\mathrm{Fu}$ et al. and 2030, 2050, 2070 in this study) or at the spatial scale employed. 


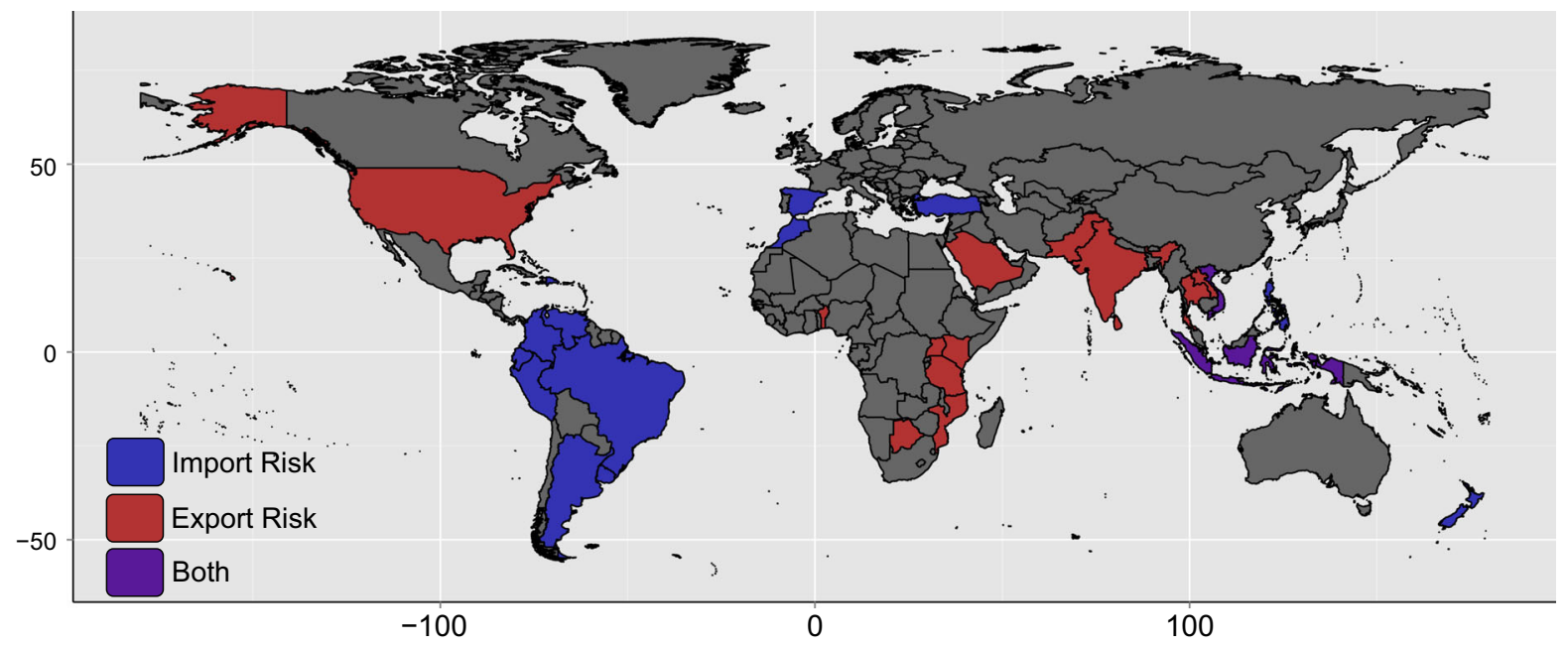

Fig. 5 Map of countries ranked based on holding suitable climate space, high fruit production and suitable trade indices for ten different tephritid species. Red shading indicates that these are the top 15 countries that pose an export risk of an invasive

Another potential source of variability across our results is the use of a different climate dataset, CliMond, to what most of the species where calibrated on. As CLIMEX parameters are sensitive to both changes in spatial resolution (Kriticos and Leriche 2010; Taylor and Kumar 2012) and differences in the underlying climate data, there is potential that use of a different climate dataset has contributed to slight under- or overpredictions, but unlikely to result in a systematic bias in any particular direction. These factors, among others are all known to contribute to differences between SDM studies and such errors in prediction need to be taken into account when interpreting results (Elith and Leathwick 2009; Synes and Osborne 2011). We therefore recommend that any study interested in determining a single-species risk assessment for any of these species assess the possible influence of model training data quality and spatial scale for their suitability prior to management or risk forecasting.

The models herein also describe an increase in predicted climate suitability for Rhagoletis pomonella under climate change. This may be at least partially due to Rhagoletis species having a narrower thermal niche than the other species considered here (Table 1) and that it is primarily a temperate species. Thus climate change predictions generally forecast a range expansion into higher latitudes. In terms of host range, Rhagoletis species are also specialist exploiters rather than tephritid. Blue shading indicates that these 15 countries have a risk of importing an invasive tephritid. Countries that hold both risks are shaded purple

opportunistic broad range exploiters (e.g. Anastrepha, Bactrocera, Ceratitis; Aluja and Mangan 2008), which must be considered when making more targeted assessments of response to climate change for this genus. Additionally, species like B. latifrons and Z. cucurbitae are restricted to host plants in the Solanaceae and Cucurbitaceae, respectively, and our approach therefore generalises this aspect of the species biology. However, the ubiquity of such host plants is not likely to be restrictive at a global scale, and correlating distributions with total fruit production should also capture respective hosts. Our results present an interesting comparison to a similar study that examined 15 species of invasive ants and climate change (Bertelsmeier et al. 2015). Overall, a decline in global climate suitability was demonstrated for the ant species investigated, although five of the species did display potential for range expansion (Bertelsmeier et al. 2015). Thus for two major groups of invasive insects, ants and fruit flies, climate change is not expected to broadly favour invasions, though both groups hold some notable exceptions.

While there are some significant benefits to applying CLIMEX to a group of species such as the tephritid flies examined here, caveats apply to the interpretation of these models. First, broad scale climatic variables $\left(\sim 50 \mathrm{~km}^{2}\right)$ are estimated and forecast at a vastly different scale relative to most organisms including fruit flies. Effective regional management of the 
individual species will require that finer temporal and spatial scales be employed. Tephritid flies typically use habitats on the scales of orchards and the trees within them, representing a range of microclimates that can buffer against the broad scale climatic conditions (see Barton and Terblanche 2014), although capable of long-distance dispersal in a small fraction of the population. Microclimates that provide refuges from climatic change may also be facilitated through local irrigation regimes that simulate rainfall and increase available moisture to buffer against desiccation (Stephens et al. 2007). Additionally, a $50 \mathrm{~km}^{2}$ grid cell is the product of much statistical downscaling and interpolation (Austin and Van Niel 2011), and thus the value it holds represents a long term average across a large area for a particular variable, typically not incorporating much variation. The physiological parameters used in CLIMEX models are typically grounded on laboratory data and seldom incorporate environmental heterogeneity, nor diurnal ranges of temperature or microclimatic effects (Geng et al. 2011). To the degree that especially native distributions may be constrained by biotic interactions (e.g., competition, natural enemies), may lead to underestimates of potential distributions in introduced regions (Stephens et al. 2007). Studies attempting to predict the future impacts of these invasive insects and response to climate change should also move beyond static parameter estimates and investigate adaptive variation and plasticity of traits that are involved with resistance to stresses (cold, heat, desiccation etc.) that define range limits and invasiveness (e.g. Chown et al. 2007; Hill et al. 2013) including establishment success. Rapid trait adaptation in invasive insects may facilitate persistence in a novel environment (Gibert et al. 2016), including climate change. CLIMEX models thus serve as an important tool to detect patterns of invasion and highlight differences of these patterns across species, rather than specific risk assessments.

Although climate suitability is a prerequisite for invasion and can be used as a guide to help predict and hopefully prevent future invasions, propagule pressure and host availability are also critical to invasion success (Ward and Masters 2007; Bacon et al. 2014). To comprehensively combine host information and propagule pressure is a challenging task, as future trade and fruit production projections are largely unavailable in public repositories. Insect introductions are typically accidental and driven through hitchhiking on plant material, soil and wood products (Desurmont and Pearse 2014; Liebhold et al. 2016) and many interceptions of some species of tephritid are from individual people carrying fruit across borders (Ma et al. 2012). Thus while our use of trade data and fruit production as proxies for propagule pressure and host availability are large assumptions, we anticipate there will be correlation with the actual processes underlying tephritid invasions. To forecast agricultural production and trade links accurately will require that ecologists work with economists in a pest risk analysis framework (Baker et al. 2000) to determine how trade partners are likely to change over the next century, and how new trading opportunities into foreign markets may alter invasion risk of fruit flies and other invasive species (see Nuñez and Pauchard 2010).

In examining how the potential additive effects of climate suitability, host availability (fruit production by country) and propagule pressure (trade) contribute to invasion success, the tephritid species were weighted equally and no competition was incorporated into our models. Interactions with endemic species (particularly other tephritids), and other invasive species that occupy similar niches to these (Duyck et al. 2004, 2007) is an important factor that contributes to the success of invasions, particularly at a local scale and on islands. For example, Bactrocera dorsalis outcompetes a range of other invasive tephritids when they have come into contact (see Duyck et al. 2004 for review) and B. tryoni competitively displaced $C$. capitata when their distributions overlapped in Australia (Duyck et al. 2004). We also assumed that the species are not limited by seasonal fruit availability, particularly for winter, which is not only likely to influence the range of some of these species (Stephens et al. 2007), but also their competitive ability. Competitive interactions are, however, unlikely to strongly influence the broad scale distribution assessment employed here (Pearson and Dawson 2003).

Fruit fly invasions under climate change will challenge global, regional and local food security, and the high variability in potential tephritid invasions from multiple sources will complicate future management issues regionally. Regions such as South America, and sub-Saharan Africa (i.e., those with economically important fruit production and developing markets) will likely be forced to maintain strict 
quarantine, particularly where export to the Northern Hemisphere or when another climatically suitable, uninvaded region predominates (e.g. Stephens et al. 2007). Due to the economic importance of tephritid species, understanding how climate change will influence the probability and severity of future invasions will be paramount for developing trade relations and economic security.

Acknowledgments The paper had its origin at a workshop on "Drivers, impacts, mechanisms and adaptation in insect invasions" hosted by the DST-NRF Centre of Excellence for Invasion Biology in Stellenbosch, South Africa, in November 2014. Additional financial support was provided by HortGro, the National Research Foundation of South Africa, Stellenbosch University, and SubTrop.

\section{References}

Aluja M, Mangan RL (2008) Fruit fly (Diptera: Tephritidae) host status determination: critical conceptual, methodological, and regulatory considerations. Annu Rev Entomol 53:473-502

Austin MP, Van Niel KP (2011) Improving species distribution models for climate change studies: variable selection and scale. J Biogeogr 38:1-8

Bacon SJ, Aebi A, Calanca P, Bacher S (2014) Quarantine arthropod invasions in Europe: the role of climate, hosts and propagule pressure. Divers Distrib 20:84-94

Baker RHA, Sansford CE, Jarvis CH, Cannon RJC, MacLeod A, Walters KFA (2000) The role of climatic mapping in predicting the potential geographical distribution of nonindigenous pests under current and future climates. Agric Ecosyst Environ 82:57-71

Bale JS, Masters GJ, Hodkinson ID, Awmack C et al (2002) Herbivory in global climate change research: direct effects of rising temperature on insect herbivores. Glob Change Biol 8:1-16

Barton MG, Terblanche JS (2014) Predicting performance and survival across topographically heterogeneous landscapes: the global pest insect Helicoverpa armigera (Hübner, 1808) (Lepidoptera: Noctuidae). Austral Entomol 53:249-258

Baselga A (2010) Partitioning the turnover and nestedness components of beta diversity. Glob Ecol Biogeogr 19:134-143

Bebber DP, Ramotowski MAT, Gurr SJ (2013) Crop pests and pathogens move polewards in a warming world. Nat Clim Change 3:985-988

Bertelsmeier C, Luque GM, Courchamp F (2013a) Increase in quantity and quality of suitable areas for invasive species as climate changes. Conserv Biol 27:1458-1467

Bertelsmeier C, Luque GM, Courchamp F (2013b) The impact of climate change changes over time. Biol Conserv 16:107-115

Bertelsmeier C, Luque GM, Hoffmann BD, Courchamp F (2015) Worldwide ant invasions under climate change. Biodivers Conserv 24:117-128
Bishop T, Robertson MP, van Rensburg BJ, Parr CL (2015) Contrasting species and functional beta diversity in montane ant assemblages. J Biogeogr 42:1776-1786

Brook BW, Sodhi NS, Bradshaw CJA (2008) Synergies among extinction drivers under global change. Trends Ecol Evol 23:453-460

Chown SL, Slabber S, McGeoch MA, Janion C, Leinaas HP (2007) Phenotypic plasticity mediates climate change responses among invasive and indigenous arthropods. Proc R Soc B 274:2531-2537

De Meyer M, Robertson MP, Peterson AT, Mansell MW (2008) Ecological niches and potential geographical distributions of Mediterranean fruit fly (Ceratitis capitata) and Natal fruit fly (Ceratitis rosa). J Biogeogr 35:270-281

de Villiers M, Hattingh V, Kriticos DJ (2013) Combining field phenological observations with distribution data to model the potential distribution of the fruit fly Ceratitis rosa Karsch (Diptera: Tephritidae). Bull Entomol Res 103:60-73

Delean S, Bull CM, Brook BW, Heard LMB, Fordham DA (2013) Using plant distributions to predict the current and future range of a rare lizard. Divers Distrib 19:1125-1137

Desurmont GA, Pearse IS (2014) Alien plants versus alien herbivores: does it matter who is non-native in a novel trophic interaction? Curr Opin Insect Sci 2:20-25

Dukes JS, Pontius J, Orwig D et al (2009) Responses of insect pests, pathogens, and invasive plant species to climate change in the forests of northeastern North America: What can we predict? Can J For Res 39:231-248

Duyck PF, David P, Quilici S (2004) A review of relationships between interspecific competition and invasions in fruit flies (Diptera: Tephritidae). Ecol Entomol 29:511-520

Duyck PF, David P, Quilici S (2007) Can more K-selected species be better invaders? A case study of fruit flies in La Réunion. Divers Distrib 13:535-543

Elith J, Leathwick JR (2009) Species distribution models: ecological explanation and prediction across space and time. Annu Rev Ecol Syst 40:677-697

FAO (Food and Agriculture Organization of the United Nations) Statistics Division Database. http://faostat3.fao.org/ download/Q/QC/E. Accessed July 2015

Fitzpatrick MC, Weltzin JF, Sanders N et al (2007) The biogeography of prediction error: why does the introduced range of the fire ant over-predict its native range? Glob Ecol Biogeogr 16:24-33

Fu L, Li ZH, Huang GS, Wu XX, Ni WL, Qü WW (2014) The current and future potential geographic range of West Indian fruit fly, Anastrepha obliqua (Diptera: Tephritidae). Insect Sci 21:234-244

Geng J, Li ZH, Rajotte EG, Wan FH, Lu XY, Wang ZL (2011) Potential geographical distribution of Rhagoletis pomonella (Diptera: Tephritidae) in China. Insect Sci 18:575-582

Gibert P, Hill MP, Pascual M, Plantamp C, Terblanche JS (2016) Drosophila as models to understand the adaptive process during invasion. Biol Invasions. doi:10.1007/ s10530-016-1087-4

Gutierrez AP, Ponti L (2014) Analysis of invasive insects: links to climate change. In: Ziska L, Dukes J (eds) Invasive species and global climate change. CABI, Croydon, pp 45-61

Harrington R, Clark SJ, Welham SJ et al (2007) Environmental change and the phenology of European aphids. Glob Change Biol 13:1550-1564 
Hellmann JJ, Byers JE, Bierwagen BG, Dukes JS (2008) Five potential consequences of climate change for invasive species. Conserv Biol 22:534-543

Hijmans RJ (2015) Raster: geographic data analysis and modeling. R package version 2.3-40. http://CRAN.R-project. org/package=raster

Hijmans RJ, Phillips S, Leathwick J, Elith J (2015) Package 'dismo'-species distribution modelling. R package version 1.0-12 http://cran.r-project.org/web/packages/dismo/ index.html

Hill MP, Terblanche JS (2014) Niche overlap of congeneric invaders supports a single-species hypothesis and provides insight into future invasion risk: implications for global management of the Bactrocera dorsalis complex. PLoS One 9:e90121. doi:10.1371/journal.pone.0090121

Hill MP, Chown SL, Hoffmann AA (2013) A predicted niche shift corresponds with increased thermal resistance in an invasive mite, Halotydeus destructor. Glob Ecol Biogeogr 22:942-951

Hill MP, Axford JK, Hoffmann AA (2014) Predicting the spread of Aedes albopictus in Australia under current and future climates: multiple approaches and datasets to incorporate potential evolutionary divergence. Aust Ecol 39:469-478

IPCC (2007) Climate change 2007: the physical science basis. In: Solomon S, Qin D, Manning M, Chen Z, Marquis M, Averyt KB, Tignor M, Miller HL (eds) Contribution of working group $\mathrm{i}$ to the fourth assessment report of the intergovernmental panel on climate change. Cambridge University Press, Cambridge

Jian G, Zhihong L, Fanghao W, Zhiling W (2008) Analysis of the suitability of Mexican fruit fly, Anastrepha ludens in China. Plant Prot 4:024

Jiménez-Valverde A, Peterson AT, Soberón J, Overton JM, Aragón P, Lobo JM (2011) Use of niche models in invasive species risk assessments. Biol Invasions 13:2785-2797

Karsten M, Jansen van Vuuren B, Addison P, Terblanche JS (2015) Deconstructing intercontinental invasion pathway hypotheses of the Mediterranean fruit fly (Ceratitis capitata) using a Bayesian inference approach: are port interceptions and quarantine protocols successfully preventing new invasions? Divers Distrib 21:813-825

Kriticos DJ, Leriche A (2010) The effects of climate data precision on fitting and projecting species niche models. Ecography 33:115-127

Kriticos DJ, Webber BL, Leriche A, Ota N, Macadam I, Bathols J, Scott JK (2012) CliMond: global high-resolution historical and future scenario climate surfaces for bioclimatic modelling. Methods Ecol Evol 3:53-64

Kumar S, Neven LG, Yee WL (2014) Assessing the potential for establishment of western cherry fruit fly using ecological niche modeling. J Econ Entomol 107:1032-1044

Lantschner MV, Villacide JM, Garnas JR, Croft P, Carnegie AJ, Liebhold AM, Corley JC (2014) Temperature explains variable spread rates of the invasive woodwasp Sirex noctilio in the Southern Hemisphere. Biol Invasions 16:329-339

Lenoir J, Svenning JC (2015) Climate-related range shifts-a global multidimensional synthesis and new research directions. Ecography 38:15-28

Liebhold AM, Work TT, McCullough DG, Cavey JF (2006) Airline baggage as a pathway for alien insect species invading the United States. Am Entomol 52:48-54
Liebhold AM, Yamanaka T, Roques A, Augustin S, Chown SL, Brockerhoff EG, Pyšek P (2016) Global compositional variation among native and non-native regional insect assemblages emphasizes the importance of pathways. Biol Invasions. doi:10.1007/s10530-016-1079-4

Lingbin K, Wei L, Zhong L, Fanghao W, Zhiling W, Guansheng $\mathrm{H}$ (2008) A predication of potential geographic distribution of melon fruit fly based on CLIMEX and DIVA-GIS. Acta Phytophylacica Sin 2:010

Lozier JD, Mills NJ (2011) Predicting the potential invasive range of light brown apple moth (Epiphyas postvittana) using biologically informed and correlative species distribution models. Biol Invasions 13:2409-2421

Lu W, Yuliang D, Li Z, Wei L, Fanghao A, Zhiling W (2010) A prediction of potential geographical distribution of guava fruit fly, Bactrocera (Bactrocera) correcta (Bezzi) in China. Acta Phytophylacica Sin 6:010

Ma X, Li Z, Ni W, Qu W, Wu J, Wan F, Hu X (2012) The current and future potential geographical distribution of the solanum fruit fly Bactrocera latifrons (Diptera: Tephritidae) in China. In: Li D, Chen Y (eds) Computer and computing technologies in agriculture V. Springer, Berlin, pp 236-246

Macfadyen S, Kriticos DJ (2012) Modelling the geographical range of a species with variable life-history. PLoS One 7:e40313. doi:10.1371/journal.pone.0040313

Manrakhan A, Hattingh V, Venter JH, Holtzhausen M (2011) Eradication of Bactrocera invadens (Diptera: Tephiritidae) in Limpopo province, South Africa. African Entomol 19:650-659

Mika AM, Newman JA (2010) Climate change scenarios and models yield conflicting predictions about the future risk of an invasive species in North America. Agr For Entomol $12: 213-221$

Ni WL, Li ZH, Chen HJ, Wan FH, Qu WW, Zhang Z, Kriticos DJ (2012) Including climate change in pest risk assessment: the peach fruit fly, Bactorcera zonata (Diptera: Tephritidae). Bull Entomol Res 102:173-183

Nuñez MA, Pauchard A (2010) Biological invasions in developing and developed countries: does one model fit all? Biol Invasions 12:707-714

Papadopoulos NT, Plant RE, Carey JR (2013) From trickle to flood: the large-scale, cryptic invasion of California by tropical fruit flies. Proc R Soc B 280:20131466. doi:10. 1098/rspb.2013.1466

Patz JA, Campbell-Lendrum D, Holloway T et al (2005) Impact of regional climate change on human health. Nature 438:310-317

Pearson RG, Dawson TP (2003) Predicting the impacts of climate change on the distribution of species: are bioclimate envelope models useful? Glob Ecol Biogeogr 12:361-371

Pebesma EJ, RS Bivand (2005). Classes and methods for spatial data in R. R News 5 (2). http://cran.r-project.org/doc/Rnews/

R Core Team (2015) R: a language and environment for statistical computing. R Foundation for Statistical Computing, Vienna, Austria. http://www.R-project.org/

Schutze MK, Aketarawong N, Amornsak W et al (2015) Synonymization of key pest species within the Bactrocera dorsalis species complex (Diptera: Tephritidae): taxonomic changes based on a review of 20 years of integrative morphological, molecular, cytogenetic, behavioural and chemoecological data. Syst Entomol 40:456-471 
Stephens AEA, Kriticos DJ, Leriche A (2007) The current and future potential geographical distribution of the oriental fruit fly, Bactrocera dorsalis (Diptera: Tephritidae). Bull Entomol Res 97:369-378

Sutherst RW, Maywald GF (1985) A computerised system for matching climates in ecology. Agric Ecosyst Environ 13:281-299

Sutherst RW, Maywald GF (2005) A climate model of the red imported fire ant, Solenopsis invicta Buren (Hymenoptera: Formicidae): implications for invasion of new regions, particularly Oceania. Environ Entomol 34:317-335

Sutherst RW, Maywald GF, Bourne AS (2007) Including species interactions in risk assessments for global change. Glob Change Biol 13:1-17

Synes NW, Osborne PE (2011) Choice of predictor variables as a source of uncertainty in continental-scale species distribution modelling under climate change. Glob Ecol Biogeogr 20:904-914

Taylor S, Kumar L (2012) Sensitivity analysis of CLIMEX parameters in modelling potential distribution of Lantana camara L. PLoS One 7:e40969

Thuiller W (2007) Biodiversity: climate change and the ecologist. Nature 448:550-552

Tscharntke T, Klein AM, Kruess A, Steffan-Dewenter I, Thies C (2005) Landscape perspectives on agricultural intensification and biodiversity-ecosystem service management. Ecol Lett 8:857-874

Vera MT, Rodriguez R, Segura DF, Cladera JL, Sutherst RW (2002) Potential geographical distribution of the
Mediterranean fruit fly, Ceratitis capitata (Diptera: Tephritidae), with emphasis on Argentina and Australia. Environ Entomol 31:1009-1022

Virgilio M, Jordaens K, Verwimp C, White IM, De Meyer M (2015) Higher phylogeny of frugivorous flies (Diptera, Tephritidae, Dacini): localised partition conflicts and a novel generic classification. Mol Phylogenet Evol 85:171-179

Walther GR, Roques A, Hulme PE et al (2009) Alien species in a warmer world: risks and opportunities. Trends Ecol Evol 24:686-693

Ward NL, Masters GJ (2007) Linking climate change and species invasion: an illustration using insect herbivores. Glob Change Biol 13:1605-1615

Webber BL, Yates CJ, Le Maitre DC et al (2011) Modelling horses for novel climate courses: insights from projecting potential distributions of native and alien Australian acacias with correlative and mechanistic models. Divers Distrib 17:978-1000

Yamanaka T, Morimoto N, Nishida GM, Kiritani K, Moriya S, Liebhold AM (2015) Comparison of insect invasions in North America. Biol Invasions, Japan and their Islands. doi:10.1007/s10530-015-0935-y

Yonow T, Sutherst RW (1998) The geographical distribution of the Queensland fruit fly, Bactrocera (Dacus) tryoni, in relation to climate. Aust J Agric Res 49:935-953

Ziska LH, Blumenthal DM, Runion GB, Hunt ER Jr, DiazSoltero H (2011) Invasive species and climate change: an agronomic perspective. Clim Change 105:13-42 